\title{
Influence of provider experience on antiretroviral adherence and viral suppression
}

\author{
This article was published in the following Dove Press journal: \\ HIVIAIDS - Research and Palliative Care \\ 14 August 2012 \\ Number of times this article has been viewed
}

\author{
Michael A Horberg ${ }^{1,2}$ \\ Leo B Hurley ${ }^{2,3}$ \\ William J Towner ${ }^{4}$ \\ Michael W Allerton ${ }^{3}$ \\ Beth T Tang ${ }^{5}$ \\ Sheryl L Catz ${ }^{6}$ \\ Michael J Silverberg ${ }^{2,3}$ \\ Charles P Quesenberry ${ }^{3}$
}

'Mid-Atlantic Permanente Research Institute, Rockville, MD, USA; ${ }^{2} \mathrm{HIV}$ Initiative, Kaiser Permanente, Oakland, CA, USA; ${ }^{3}$ Kaiser Permanente Northern California, Oakland, CA, USA; ${ }^{4}$ Kaiser Permanente Southern California, Los Angeles, CA, USA; ${ }^{5}$ Research and Evaluation, Kaiser Permanente Southern California, Pasadena, CA, USA; ${ }^{6}$ Group Health Research Institute, Seattle, WA, USA
Correspondence: Michael Horberg Executive Director Research, MidAtlantic Permanente Research Institute, 210I East Jefferson Street, 3 West,

Rockville, MD 20852, USA

$\mathrm{Tel}+\mathrm{I} 3018166302$

Fax +13018167115

Email michael.horberg@kp.org
Background and aim: Early in the combination antiretroviral therapy (cART) era, provider experience (as measured by panel size) was associated with improved outcomes. We explored that association and other characteristics of provider experience.

Methods: We performed a retrospective cohort analysis in Kaiser Permanente California (an integrated health care system in the United States), examining all human immunodeficiency virus seropositive $(\mathrm{HIV}+)$ patients initiating a first cART regimen (antiretroviral therapy [ART]naïve, $\mathrm{N}=7071$ ) or initiating a second or later cART regimen (ART-experienced, $\mathrm{N}=3730$ ) from 1996-2006. We measured ART adherence through 12 months (pharmacy fill and refill records) and determined HIV viral load levels below limits of quantification at 12 months. Provider experience, updated annually, was measured as (1) HIV panel size (0-10 patients as reference strata), (2) years treating HIV (less than 1 year as reference), and (3) specialty (noninfectious disease specialty, non-HIV expert as reference). We assessed associations by utilizing mixed modeling analyses (clustered by provider and medical center), controlling for patient age, sex, race/ethnicity, HIV risk behavior, hepatitis $\mathrm{C}$ coinfection, ART regimen class, and calendar year.

Results: Among the ART-experienced, improved adherence was associated with greater years experience (mean increase 3.1\% 2-5 years experience; 3.7\% 5-10 years; 2.7\% 11-20 years; $P=0.07$, categorical). In adjusted analyses, viral suppression among ART-naïve was positively associated with panel size (odds ratio $26-50$ patients: $1.31, P=0.03$, categorical), but negatively associated with years experience ( $18 \%$ less for greater than 100 patients; $P=0.003)$. No provider characteristic was significantly associated with improved adherence among ART-naïve or odds of maximal viral suppression among ART-experienced in adjusted analysis.

Conclusions: Except for panel size and years experience among ART-naïve, provider characteristics did not significantly influence ART adherence or likelihood of viral suppression.

Keywords: antiretroviral therapy, adherence, provider-level factors, HIV-related outcomes

\section{Introduction}

Successful human immunodeficiency virus (HIV) care involves many factors, including maximal antiretroviral therapy (ART) adherence, optimal viral control, management of comorbidities and medication adverse effects. In addition to patient-level factors, care system and provider factors also significantly impact HIV-related outcome measures. ${ }^{1}$ Early in the combination ART (cART) era, multidisciplinary care teams were found to be associated with improved outcomes. ${ }^{2,3}$

Although many care team components likely have an effect on outcomes, the provider has unique responsibilities, including recommending when to start cART, 
what medications to use, and when to change cART. For most chronic diseases, the provider is considered a key element of the patient-centered medical home and multidisciplinary care team. Certain provider-level factors have been shown to influence ART adherence, ${ }^{1}$ but these studies have not been updated in the more recent cART era. In the pre2000 cART era, greater provider experience (as measured by HIV+ patient panel size) was associated with improved survival and increased ART use. ${ }^{4-8}$ Studies indicated that physicians with larger panel sizes (a surrogate for greater provider experience) and infectious disease specialists were more likely to follow HIV care guidelines and to emphasize ART adherence with patients. ${ }^{9,10}$ However, primary care physicians with high levels of HIV care experience were apt to see their patients more frequently, utilize more laboratory and pharmacy services, and have better survival statistics than less experienced primary care physicians. ${ }^{11}$ None of these studies, though, are in the more recent cART era, nor do they account for combinations of provider-level factors (years experience, panel size, specialization).

Kaiser Permanente (KP) is the largest civilian provider of integrated HIV care in the United States. Based on KP HIV registries and State of California statistics, KP California serves $12 \%$ of California's HIV-infected population. ${ }^{12} \mathrm{We}$ utilized the diversity of our provider population to explore the impact of provider characteristics, specifically HIV patient panel size, years of HIV treatment experience, and specialty on HIV-related outcomes of ART adherence and viral suppression.

\section{Methods}

\section{Study design}

We performed a retrospective cohort analysis of all HIVinfected patients initiating a new cART regimen in KP California from 1996-2006 and followed for up to 12 months. We stratified by ART experience, defining ART-naïve as patients having no prior ART experience. We measured ART adherence through 12 months postregimen initiation and HIV RNA below limits of quantification (BLQ) at 12 months postregimen initiation. We analyzed provider HIV panel size, years of HIV care experience, and provider specialization impact on these two outcome measures, further adjusting for various patient and cART regimen factors.

\section{Subjects}

KP California is an integrated health care system with 26 medical centers serving $18.3 \%$ of the California population and $12 \%$ of its HIV-infected population. ${ }^{12,13}$ Patients in
KP receive multidisciplinary health care, including HIV. The $\mathrm{HIV}+$ population in KP is demographically representative of the state; ${ }^{14}$ data indicate that members overall are very similar to the general population with regard to age, sex, and race/ethnicity, with only slight underrepresentation of those in lower and higher income and education categories. ${ }^{15}$

We identified all HIV antibody seropositive (HIV+) patients at least 18 years old initiating a first or new cART regimen dispensed from a KP pharmacy in the years 19962006, where the HIV viral load level prior to starting the new regimen was above lower limits of quantification. We classified the patients associated with the cART regimen as ART-naïve if they had no record of any prior antiretroviral use; otherwise, new regimens were classified as they were those for ART-experienced patients. We defined a cART regimen among ART-naïve patients as at least three antiretroviral drugs used in combination consistent with United States Department of Health and Human Services antiretroviral therapy guidelines, ${ }^{16}$ with ritonavir at doses at less than or equal to $400 \mathrm{mg}$ per day not considered as an active drug in the regimen. New regimens (those among patients with prior exposure to ART) were defined as at least two antiretroviral drugs not previously used by that patient. Eligible patients had at least 6 months KP membership prior to initiation of the first or new regimen in order for baseline values to be determined and presence of prior antiretroviral history to be established.

\section{Measurements}

KP pharmacy records provide details of each antiretroviral dispensed to a patient which allowed us to assess date of first antiretroviral prescription fill and regimen composition, as well as identify refills for patients during study follow-up. Adherence to the cART regimen over the 12-month observation period was calculated using established methods developed for administrative pharmacy databases. These methods account for all of the component medicines of an individual patient's ART regimen. ${ }^{17-20}$ This measure of adherence is computed across all antiretroviral medications as the number of doses in an interval (bounded by a first and last fill date of drug, requiring at least two fills per drug) for which the patient has drug in possession as a percentage of total intended doses in the span between the first and last filling. The computation takes quantity supplied and frequency of dosing into account. Employing pharmacy records to ascertain ART adherence has been validated and widely used in previous studies at other institutions and $\mathrm{KP}^{21,22}$ We classified cART regimens as nonnucleoside reverse transcriptase inhibitor (NNRTI)-based, nucleoside 
reverse transcriptase inhibitor (NRTI) only, protease inhibitor (PI)-based, PI+NNRTI, or other. We also measured HIV viral load closest to regimen initiation and 12 months postinitiation. We defined BLQ as less than 500 copies/mL through 2000 and less than 75 copies/mL subsequently.

We determined the first year of providing HIV care posttraining (which included any fellowship) for all HIV care providers in KP California. We used that year to calculate the provider's years experience at the time each patient initiated the ART regimen of interest. From our HIV registries, we determined the HIV panel size of each provider as of July 1 of the patient's ART regimen initiation year. We classified each provider's HIV specialty designation as: infectious disease (ID) specialist; non-ID, but HIV expert; non-ID and non-HIV expert provider; HIV nurse practitioner; or HIV physician assistant. Non-ID, but HIV expert was determined as meeting HIV Medicine Association or American Academy of HIV Medicine criteria for HIV "specialization"/ expertise. $^{23,24}$

\section{Statistical analysis}

Our primary predictor variables were the various characteristics of HIV care providers. We calculated the percentage of patients below limits of quantification (BLQ) at 12 months, stratified by ART-experienced/naïve for the various provider characteristics. For all analyses, we categorized HIV panel size as 0-10 (reference), 11-25, 26-50, 51-100, and >100 patients; and we categorized years of HIV care experience as $\leq 1$ (reference), 2-5, 6-10, 11-20, and $>20$ years. NonID, non-HIV physician was the reference designation for provider specialty.

All multivariable analyses were conducted for ARTnaïve and -experienced patients separately, since adherence and BLQ results are quite different for these patients. ${ }^{25}$ In the same model, we evaluated the association between provider characteristics as defined above and ART adherence by employing mixed linear regression with clustering by provider and medical center. We further adjusted for various patient and regimen level factors associated with adherence, including age, sex, race/ethnicity (categorized as Caucasian, Black, Latino, other/unknown), HIV risk behavior (categorized as men having sex with men, injection drug use [IDU], heterosexual transmission, or other/unknown), known history of hepatitis $\mathrm{C}$ infection, cART regimen class, and year regimen initiated. We employed the same approach to the analysis of odds of BLQ, using mixed logistic regression with clustering by provider and medical center and the same additional variables for the adjusted analysis. We employed a statistical level of $P<0.05$ for significance. Analyses performed using Stata v 10.0 (Stata Corp, College Station, TX).

We obtained approval from KP Institutional Review Boards with waiver of informed consent.

\section{Results}

We analyzed 7597 cART regimen starts among the cohort of 7071 ART-naïve patients and 3814 cART starts among the cohort of 3730 ART-experienced patients (18\% of patients provided data for both ART-naïve and -experienced regimens). Baseline characteristics of the two cohorts are presented in Table 1. For both cohorts, the majority of patients were male, Caucasian, and men having sex with men, reflecting the epidemic in California. ${ }^{12}$ There was statistical heterogeneity between the two groups for many of the demographic and regimen characteristics (including age distribution, sex, race/ ethnicity, and ART class of cART regimen), but the differences did not appear to be clinically significant. Of the ART-naïve and -experienced regimen starts, $47.2 \%$ were from 2001 and more recently. The majority of both cohorts had a PI-based regimen, but over $35 \%$ in both cohorts also were exposed to NNRTI medications. Overall mean ART adherence was $>85 \%$ for both groups. While a majority of providers were not HIV experts (Table 1), a majority of the patients were cared for by infectious disease or HIV experts (Tables 2 and 3).

Among the ART-naïve patients, overall mean ART adherence was $92.5 \%$ (interquartile range [IQR]: 77.0\%-98.7\%). The crude results (Table 2 ) indicate that adherence improved with generally larger HIV panel size and greater years' provider experience. However, among the ART-experienced (Table 3), there was no such trend. The overall mean adherence among the ART-experienced was $87.5 \%$ (IQR: $70.5 \%-96.8 \%$ ). Both cohorts had increased percentage of BLQ with larger panel sizes.

Tables 2 and 3 provide the multivariate analyses for ART adherence for the ART-naïve and -experienced patients respectively. Among the ART-naïve, in univariate analysis, only increased panel size was associated with improved adherence $(P<0.001)$. However, this association was no longer observed in the adjusted analysis. In fact, no stratum of any provider level factor was significantly associated with improved adherence in the adjusted analyses. Other factors associated with improved adherence $(P<0.05)$ were greater age and calendar year. Factors associated with lower ART adherence among ART-naïve patients were Black and Latino race/ethnicity, IDU, and PI-based regimens.

Among the ART-experienced patients, years of provider HIV care experience were associated with improved 
Table I Characteristics of patients and provider level data at regimen start

\begin{tabular}{|c|c|c|c|c|c|}
\hline \multirow[t]{2}{*}{ Variable } & \multicolumn{2}{|c|}{ Antiretroviral-naïve patients } & \multicolumn{2}{|c|}{ Antiretroviral-experienced patients } & \multirow[t]{2}{*}{$P$ value } \\
\hline & $\begin{array}{l}\text { Patient } \\
\text { characteristics }\end{array}$ & $\begin{array}{l}\text { Provider } \\
\text { characteristics }\end{array}$ & $\begin{array}{l}\text { Patient } \\
\text { characteristics }\end{array}$ & $\begin{array}{l}\text { Provider } \\
\text { characteristics }\end{array}$ & \\
\hline Total number of unique patients [number $(\mathrm{N})$ ] & 7071 & 533 & 3730 & 219 & \\
\hline $\begin{array}{l}\text { Total number of combination antiretroviral } \\
\text { therapy regimens analyzed }[\mathrm{N}]\end{array}$ & 7597 & & 3814 & & \\
\hline Age: median (interquartile range) & $41(35-48)$ & & $43(37-49)$ & & 0.02 \\
\hline Male: [N (\%)] & $6314(89.3)$ & & $3420(91.7)$ & & $<0.001$ \\
\hline Race/ethnicity (known) [N (\%)] & & & & & 0.001 \\
\hline Caucasian & $3627(51.3)$ & & $2100(56.3)$ & & \\
\hline Black & $|42|(20.1)$ & & $750(18.3)$ & & \\
\hline Latino & $1669(23.6)$ & & $806(21.6)$ & & \\
\hline HIV risk (known) [N (\%)] & & & & & 0.10 \\
\hline Men sex with men & $5084(71.9)$ & & $2909(78.0)$ & & \\
\hline Injection drug use & $452(6.4)$ & & $224(6.0)$ & & \\
\hline Hepatitis C coinfected [N (\%)] & $700(9.9)$ & & $395(10.6)$ & & 0.43 \\
\hline Antiretroviral class [N (\%)] & & & & & $<0.001$ \\
\hline $\begin{array}{l}\text { Nonnucleoside reverse transcriptase } \\
\text { inhibitor-based }\end{array}$ & $2750(38.9)$ & & $563(15.1)$ & & \\
\hline Nucleoside reverse transcriptase inhibitor only & $254(3.6)$ & & $153(4.1)$ & & \\
\hline Protease inhibitor-based & $3705(52.4)$ & & $2048(54.9)$ & & \\
\hline $\begin{array}{l}\text { Mixed protease inhibitor and nonnucleoside } \\
\text { reverse transcriptase inhibitor-based }\end{array}$ & $36 I(5.1)$ & & $951(25.5)$ & & \\
\hline Year of first ART prescription [N (\%)] & \multicolumn{2}{|c|}{ Unique providers in each year } & & & \\
\hline 1996 & - & - & $90(2.4)$ & 47 & \\
\hline 1997 & $1400(19.8)$ & 270 & $589(15.8)$ & 118 & \\
\hline 1998 & $877(12.4)$ & 197 & $403(10.8)$ & 110 & \\
\hline 1999 & $906(11.4)$ & 152 & $556(14.9)$ & 113 & \\
\hline 2000 & $665(9.4)$ & 129 & $332(8.9)$ & 97 & \\
\hline 2001 & $552(7.8)$ & 128 & $313(8.4)$ & 85 & \\
\hline 2002 & $537(7.6)$ & 123 & $298(8.0)$ & 82 & \\
\hline 2003 & $587(8.3)$ & 113 & $324(8.7)$ & 84 & \\
\hline 2004 & $580(8.2)$ & 126 & $339(9.1)$ & 93 & \\
\hline 2005 & $509(7.2)$ & 111 & $26 \mid(7.0)$ & 84 & \\
\hline 2006 & $566(8.0)$ & 107 & $224(6.0)$ & 81 & \\
\hline \multicolumn{6}{|l|}{ Specialty (\# providers) } \\
\hline Infectious diseases specialty & & 52 & & 51 & \\
\hline HIV, but noninfectious diseases specialty & & 32 & & 32 & \\
\hline Nurse practitioner/physician assistant & & 12 & & 10 & \\
\hline Noninfectious diseases/non-HIV & & 437 & & 126 & \\
\hline
\end{tabular}

Abbreviations: ART, antiretroviral therapy; HIV, human immunodeficiency virus.

adherence in the univariate analysis $(P=0.05$; reference less than or equal to 1 year), and three of the 4 -years' experience strata had a mean improved adherence of greater than or equal to $4.0 \%$. The association between years experience and improved adherence attenuated in the adjusted model, although both 2-5 and 6-10 years experience were significantly associated with improved adherence. Patient factors positively associated with improved adherence included increased age and calendar year, while Black, Latino, and IDU were negatively associated with ART adherence.

Among the ART-naïve and -experienced, 59.9\% and $41.9 \%$ were BLQ at 12 months, respectively, with improvement over time (ART-naïve: $53.2 \%$ in 1997 to $73.9 \%$ in 2006 ;
ART-experienced: $22.7 \%$ in 1996 to $61.4 \%$ in 2006). Odds of virologic suppression results are shown in Table 4. Among the ART-naïve, there were improved odds of achieving BLQ with increased HIV panel size. Surprisingly, there was a negative association with years experience and odds of achieving BLQ in the adjusted analysis. Again, specialty had no association with odds of achieving BLQ. Significantly associated with increased odds of achieving BLQ was increased patient age, NNRTI class, and calendar year, while Black and IDU were negatively associated with odds of achieving BLQ in this group.

While both increased panel size and greater years experience were significantly associated with greater odds of achieving 
Table 2 Antiretroviral adherence results among antiretroviral-naïe patients

\begin{tabular}{|c|c|c|c|c|c|}
\hline & \multirow{2}{*}{$\begin{array}{l}\text { Percent of total } \\
\text { patients }\end{array}$} & \multicolumn{4}{|c|}{ Difference in percent mean adherence ( $95 \%$ confidence interval) } \\
\hline & & Univariate analysis $^{\mathbf{a}}$ & $P$-value ${ }^{\mathrm{b}}$ & Adjusted analysis ${ }^{\mathrm{a}, \mathrm{c}}$ & $P$-value ${ }^{b}$ \\
\hline \multicolumn{6}{|l|}{ HIV panel size } \\
\hline $0-10$ patients & 12.4 & & Reference & & \\
\hline II-25 patients & 8.6 & $-1.0 \%(-3.2 \%$ to $+1.2 \%)$ & $<0.001$ & $-0.9 \%(-3.1 \%$ to $+1.1 \%)$ & 0.35 \\
\hline $26-50$ patients & 12.5 & $+1.7 \%(-0.4 \%$ to $+3.9 \%)$ & & $+1.1 \%(-0.9 \%$ to $+3.1 \%)$ & \\
\hline $51-100$ patients & 23.2 & $+1.5 \%(-0.5 \%$ to $+3.5 \%)$ & & $+0.1 \%(-1.7 \%$ to $+2.0 \%)$ & \\
\hline$>100$ patients & 43.4 & $+3.1 \%(+1.2 \%$ to $+5.1 \%)$ & & $+0.6 \%(-1.2 \%$ to $+2.5 \%)$ & \\
\hline \multicolumn{6}{|l|}{ Years treating HIV } \\
\hline$\leq \mathrm{I}$ year & 10.3 & & Reference & & \\
\hline $2-5$ years & 18.9 & $+0.3 \%(-1.5 \%$ to $+2.2 \%)$ & 0.20 & $-0.4 \%(-2.2 \%$ to $+1.3 \%)$ & 0.64 \\
\hline $6-10$ years & 24.2 & $-0.5 \%(-2.3 \%$ to $+1.4 \%)$ & & $-0.9 \%(-2.7 \%$ to $+0.8 \%)$ & \\
\hline II -20 years & 41.6 & $+0.7 \%(-1.2 \%$ to $+2.6 \%)$ & & $-0.8 \%(-2.5 \%$ to $+0.9 \%)$ & \\
\hline$>20$ years & 5.0 & $+2.5 \%(-0.3 \%$ to $+5.3 \%)$ & & $-2.0 \%(-4.7 \%$ to $+0.7 \%)$ & \\
\hline \multicolumn{6}{|l|}{ Specialty designation } \\
\hline Noninfectious diseases/non-HIV & 42.3 & & Reference & & \\
\hline HIV but noninfectious diseases expert & 20.0 & $+0.8 \%(-1.2 \%$ to $+2.8 \%)$ & 0.66 & $+0.2 \%(-1.6 \%$ to $+2.0 \%)$ & 0.97 \\
\hline Infectious diseases specialty & 9.9 & $+0.7 \%(-1.2 \%$ to $+2.3 \%)$ & & $-0.1 \%(-1.8 \%$ to $+1.6 \%)$ & \\
\hline Nurse practitioner/physician assistant & 27.9 & $-0.7 \%(-0.4 \%$ to $+2.4 \%)$ & & $-0.4 \%(-3.1 \%$ to $+2.2 \%)$ & \\
\hline
\end{tabular}

Notes: analysis by mixed logistic regression with clustering by provider and medical center; adjusted analysis included patient age and sex, patient race/ethnicity, HIV risk

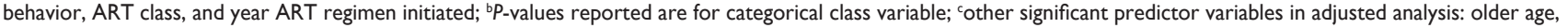
black (lower odds), Latino (lower), injection drug use (lower), Hepatitis C coinfection (lower), protease inhibitor class (lower), year ART regimen initiated.

Abbreviations: ART, antiretroviral therapy; HIV, human immunodeficiency virus.

BLQ among ART-experienced patients, this did not hold in adjusted analysis. Here, increased age and temporal trend were highly associated with increased odds of achieving BLQ (both $P<0.001)$. Again, Black race and IDU were negatively associated with odds of achieving BLQ among ART-experienced patients. Specialty designation had no impact.

\section{Discussion}

This study is significant for its consideration of different provider factors for both ART adherence and odds of viral suppression, as well as for consideration of patient and regimen level factors and stratifying by ART experience. We found in our study that the impact of provider characteristics

Table 3 Antiretroviral adherence results among antiretroviral-experienced patients

\begin{tabular}{|c|c|c|c|c|c|}
\hline & \multirow{2}{*}{$\begin{array}{l}\text { Percent of } \\
\text { total patients }\end{array}$} & \multicolumn{4}{|c|}{ Difference in percent mean adherence ( $95 \%$ confidence interval) } \\
\hline & & Univariate analysis $^{\mathbf{a}}$ & $P$-value ${ }^{b}$ & Adjusted analysis ${ }^{\mathrm{a}, \mathrm{c}}$ & $P$-value ${ }^{\text {b }}$ \\
\hline \multicolumn{6}{|l|}{ HIV panel size } \\
\hline $0-10$ patients & 6.9 & & Reference & & \\
\hline II-25 patients & 8.1 & $-2.7 \%(-6.2 \%$ to $+0.9 \%)$ & 0.60 & $-2.2 \%(-5.6 \%$ to $+1.2 \%)$ & 0.71 \\
\hline $26-50$ patients & 12.3 & $-1.3 \%(-4.8 \%$ to $+2.2 \%)$ & & $-1.5 \%(-4.8 \%$ to $+1.9 \%)$ & \\
\hline $5 \mathrm{I}-100$ patients & 21.9 & $-0.7 \%(-4.2 \%$ to $+2.9 \%)$ & & $-1.6 \%(-5.1 \%$ to $+1.9 \%)$ & \\
\hline$>100$ patients & 50.8 & $-0.8 \%(-4.3 \%$ to $+2.7 \%)$ & & $-2.2 \%(-5.6 \%$ to $+1.3 \%)$ & \\
\hline \multicolumn{6}{|l|}{ Years treating HIV } \\
\hline$\leq \mathrm{I}$ year & 6.7 & & Reference & & \\
\hline $2-5$ years & 18.0 & $+4.0 \%(+1.1 \%$ to $+7.0 \%)$ & 0.05 & $+3.1 \%(+0.2 \%$ to $+6.0 \%)$ & 0.07 \\
\hline $6-10$ years & 24.7 & $+4.3 \%(+1.4 \%$ to $+7.3 \%)$ & & $+3.7 \%(+0.9 \%$ to $+6.6 \%)$ & \\
\hline II-20 years & 44.3 & $+4.2 \%(+1.3 \%$ to $+7.1 \%)$ & & $+2.7 \%(-0.2 \%$ to $+5.5 \%)$ & \\
\hline$>20$ years & 6.3 & $+3.6 \%(-0.3 \%$ to $+7.4 \%)$ & & $+0.6 \%(-3.3 \%$ to $+4.5 \%)$ & \\
\hline \multicolumn{6}{|l|}{ Specialty designation } \\
\hline Noninfectious diseases/non-HIV & 46.0 & & Reference & & \\
\hline HIV, but noninfectious diseases expert & 22.2 & $+0.4 \%(-2.6 \%$ to $+3.3 \%)$ & 0.95 & $+1.2 \%(-1.6 \%$ to $+4.0 \%)$ & 0.66 \\
\hline Infectious diseases specialty & 9.6 & $-0.4 \%(-3.3 \%$ to $+2.5 \%)$ & & $+1.1 \%(-1.7 \%$ to $+4.0 \%)$ & \\
\hline Nurse practitioner/physician assistant & 22.1 & $-0.4 \%(-4.6 \%$ to $+3.9 \%)$ & & $-2.6 \%(-1.6 \%$ to $+6.7 \%)$ & \\
\hline
\end{tabular}

Notes: aAnalysis by mixed logistic regression with clustering by provider and medical center; adjusted analysis included patient age and sex, patient race/ethnicity, HIV risk behavior, ART class, and year ART regimen initiated; ${ }^{b}$-values reported are for categorical class variable; ' other significant predictor variables in adjusted analysis: older age, black (lower odds), Latino (lower), injection drug use (lower), Hepatitis C co-infection (lower), protease inhibitor class (lower), year ART regimen initiated.

Abbreviations: ART, antiretroviral therapy; HIV, human immunodeficiency virus. 


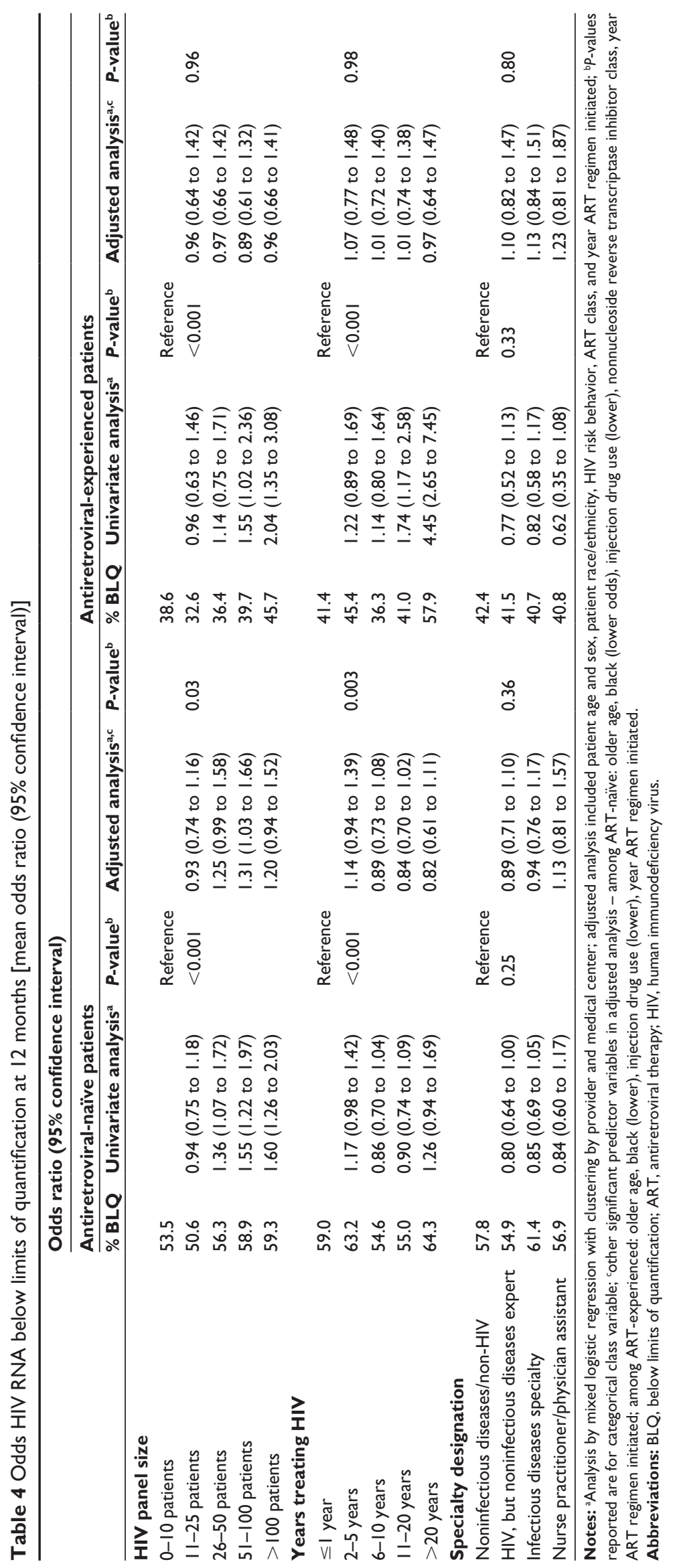


on adherence and achieving virologic suppression varies stratifying by the patient's antiretroviral status. Among antiretroviral-naïve patients, increased provider HIV panel size was associated with virologic suppression among ARTnaïve patients, while greater years of provider experience appears to have a negative association in these patients. Among ART-experienced patients, improved adherence was associated with greater number of years of provider experience, but other patient and regimen factors also had impact. For virologic suppression among ART-experienced patients, patient-level factors and temporal trend dominated over provider-level factors.

We previously have shown that ART experience (ART-naïve or not) greatly influences ART adherence and achieving maximal viral control. ${ }^{25}$ Here, we found that the associations with provider-level factors are quite different when stratified by ART experience; as such, it would have been inappropriate to analyze ART-naïve and -experienced patients in a combined model. However, HIV care clinics are not separated by ART experience, and providers must consider the needs of both ART-naïve and -experienced patients simultaneously.

In the pre-cART era, greater HIV panel size was associated with greater survival. ${ }^{26}$ Early in the cART era, increased panel size was associated with earlier adoption of ART as per national treatment guidelines. ${ }^{4,6}$ Follow-up studies also indicated that greater physician experience (degree of residency training and panel size) was associated with improved survival in the early cART era. ${ }^{11}$ No consideration in these studies was given to prior antiretroviral experience. In our analysis, panel size had some impact in adjusted analysis among antiretroviral-naïve patients for virologic suppression once other level factors were considered, but not among antiretroviral-experienced patients; which is an important distinction. However, in adjusted analysis, panel size had no effect on ART adherence regardless of ART experience. Only one prior study in the early cART era explored the association of panel size and virologic suppression; unlike us they did not see an association among the ART-naïve patients. ${ }^{6}$

Prior studies appeared to have equated panel size with years HIV care experience. ${ }^{4,11,26}$ However, we found that these factors had independent associations with our outcomes, and were influenced by the patient's ART status. For adherence, years of clinician HIV experience had no impact among ART-naïve, but did among ART-experienced patients. We did not find this surprising; ART-experienced patients already had failed at least one cART regimen, implying poorer prior adherence, which is where an experienced provider can make a difference.

Of concern is the negative association we found between years of provider experience and odds of achieving BLQ among ART-naïve patients. While none of the individual strata were statistically significant, the overall categorical variable was, and the mean odds ratios declined with greater years experience. This deserves further study; we cannot discern a reason why more experienced clinicians would have fewer virologically suppressed than less experienced clinicians. We found a similar, albeit nonsignificant, trend among the ART-experienced in the adjusted analysis, implying that unmeasured factors are affecting these results. KP patients usually go to the specific HIV clinic based on geography, not certain providers, as all KP medical centers offer HIV care. Thus, it is unlikely more challenging patients were purposely assigned to more-experienced providers.

Prior studies found that infectious disease specialists and "expert" generalists were more likely to prescribe cART than nonexpert generalists, as well as greater likelihood of achieving virologic suppression. ${ }^{6}$ We did not observe any association among specialists compared to primary care providers without HIV expertise for our outcomes. This lack of association held for all specialties considered, and between the different specialties (data not shown). We presume this lack of association is due to patient and regimen factors, including temporal trend. Additionally, our multidisciplinary HIV care model ensures some similar practice among all providers, with common care and prescribing practices, guidelines, and a common formulary. ${ }^{27,28}$ We cannot determine from our data the impact of our integrated care model on these results; however, our prior research has shown the importance of the multidisciplinary care team and clinical pharmacists for these HIV-related outcomes. ${ }^{22,29}$ Our providers communicate regularly about treatment practices, across all levels of expertise. More experienced clinicians share best practices with less experienced providers. All patients within a medical center are eligible for similar services. We do account for medical center differences in our adjusted analyses.

Patient and regimen level factors affect ART adherence and viral suppression, ${ }^{1,30}$ which our study confirms. As shown previously, we found increasing age to be associated with greater adherence and odds BLQ; ${ }^{31}$ and that IDU was associated with worse outcomes, when compared to other HIV risk behaviors. ${ }^{32,33}$ As we have shown previously, our men-having-sex-with-men patients had better outcomes than IDU patients in this study. ${ }^{22,25}$ We also found a negative association between Black race and both adherence and odds 
of achieving BLQ among both ART-naïve and -experienced patients. While we have shown this negative association with adherence previously, ${ }^{34}$ we did not see the negative association for odds of achieving BLQ. Previous studies have seen this negative association, and similar to prior data, we did not find such an association in Latinos. ${ }^{30}$

We also found that NNRTI class was associated with greater likelihood of achieving maximal viral suppression, compared to PI class among ART-naïve patients, as seen elsewhere. ${ }^{30}$ However, we did not see such an association with regimen class among ART-experienced patients. For all patient groups, there was a positive association between more recent calendar year and both improved adherence and higher odds of achieving BLQ, which has also been seen in other studies. ${ }^{30} \mathrm{We}$ are the first to demonstrate that this association holds for both antiretroviral-naïve and -experienced patients.

We acknowledge some limitations with our study. We did not assess provider attitudes about "when to start" cART or initial regimen choice, except that ART class was a covariate in the analysis, which are critical elements of provider behavior and successful outcomes, and our providers share common practices and guidelines, so we would not expect there to be significant difference here. Also, we emphasize that our study is limited to two specific outcomes - ART adherence and odds viral suppression. Other factors related to HIV care, including starting ART, which ART regimens chosen, and treatment of comorbidities, are not assessed by our study, and we make no generalizations in those regards.

Additionally, we required that patients received their medications through KP pharmacies. It is possible that ART adherence and other outcomes could be very different in patients who do not receive their medications at KP, but this percent is very small $(<4 \%)$. Missing data are always a concern, but less than $10 \%$ of patients did not have HIV risk or race/ethnicity known and we were able to show significant associations between risk and race and our investigated outcomes.

With the progress of the United States' National HIV/ AIDS Strategy, more HIV-infected patients will be identified and placed into care. ${ }^{35}$ The United States' HIV care workforce will need to expand. Our results indicate that provider characteristics including specialty may not have a significant role in achieving improved ART adherence, but larger panel size should be associated with improved virologic suppression (a clear goal of the strategy) among ART-naïve patients. These findings also apply internationally, where the goal of increased access to HIV care has clear implications for the HIV workforce. Our results should have application to HIV care team models and increasing access to HIV care.

\section{Acknowledgments}

The authors wish to thank Courtney Ellis for her assistance with manuscript preparation.

\section{Disclosure}

This study was funded by National Institute of Mental Health (NIMH) grant 1R21MH085553-01A1. Dr Silverberg was supported by grant number K01AI071725 from the National Institute of Allergy and Infectious Diseases (NIAID).

The authors note the following pertinent disclosures: Dr Horberg is an employee of Mid-Atlantic Permanente Medical Group, PC, and has active research grants from Merck, Inc (principal investigator) and Pfizer Pharmaceuticals (coinvestigator); Dr Towner is a partner in Southern California Permanente Medical Group, and is a coinvestigator on research studies funded by Merck, Inc, and Pfizer Pharmaceuticals; Dr Silverberg is an employee of The Permanente Medical Group, Inc, and has active research grants from Pfizer Pharmaceuticals (principal investigator) and Merck, Inc (coinvestigator); Dr Quesenberry is a coinvestigator on a research study funded by Merck Inc.

The data were presented in part at Infectious Disease Society of America 48th Annual Meeting, Vancouver, Canada, October, 2010, and The 6th International AIDS Society Conference on HIV Pathogenesis, Treatment and Prevention, July, 2011.

\section{References}

1. Chesney MA. Factors affecting adherence to antiretroviral therapy. Clin Infect Dis. 2000;30 Suppl 2:S171-S176.

2. Le CT, Winter TD, Boyd KJ, Ackerson L, Hurley LB. Experience with a managed care approach to HIV infection: effectiveness of an interdisciplinary team. Am J Manag Care. 1998;4(5):647-657.

3. Sherer R, Stieglitz K, Narra J, et al. HIV multidisciplinary teams work: support services improve access to and retention in HIV primary care. AIDS Care. 2002;14 Suppl 1:S31-S44.

4. Kitahata MM, Van Rompaey SE, Shields AW. Physician experience in the care of HIV-infected persons is associated with earlier adoption of new antiretroviral therapy. J Acquir Immune Defic Syndr. 2000;24(2): 106-114.

5. Landon BE, Wilson IB, Cohn SE, et al. Physician specialization and antiretroviral therapy for HIV. J Gen Intern Med. 2003;18(4):233-241.

6. Landon BE, Wilson IB, McInnes K, et al. Physician specialization and the quality of care for human immunodeficiency virus infection. Arch Intern Med. 2005;165(10):1133-1139.

7. Solomon L, Flynn C, Lavetsky G. Managed care for AIDS patients: is bigger better? J Acquir Immune Defic Syndr. 2005;38(3):342-347.

8. Wilson IB, Landon BE, Ding L, et al. A national study of the relationship of care site HIV specialization to early adoption of highly active antiretroviral therapy. Med Care. 2005;43(1):12-20. 
9. Stone VE, Mansourati FF, Poses RM, Mayer KH. Relation of physician specialty and HIV/AIDS experience to choice of guidelinerecommended antiretroviral therapy. J Gen Intern Med. 2001;16(6): 360-368.

10. Duffus WA, Barragan M, Metsch L, et al. Effect of physician specialty on counseling practices and medical referral patterns among physicians caring for disadvantaged human immunodeficiency virus-infected populations. Clin Infect Dis. 2003;36(12):1577-1584.

11. Kitahata MM, Van Rompaey SE, Dillingham PW, et al. Primary care delivery is associated with greater physician experience and improved survival among persons with AIDS. J Gen Intern Med. 2003;18(2): 95-103.

12. California Department of Health Services Office of AIDS. HIV/AIDS Surveillance Summary Reports. 2011; State HIV Statistics. Available at: http://www.cdph.ca.gov/data/statistics/Pages/OAHIVAIDSStatistics. aspx. Accessed August 1, 2011.

13. Kaiser Permanente. KP Stat Facts. 2009; Membership Data KP. Available at: http://xnet.kp.org/newscenter/aboutkp/fastfacts.html. Accessed August 1, 2011.

14. California Department of Health Services: Office of AIDS. California AIDS Surveillance Report: Cumulative Cases as of December 31, 2005. 2006. http://www.cdph.ca.gov/data/statistics/Documents/OA-200512AIDSMerged.pdf

15. Krieger N. Overcoming the absence of socioeconomic data in medical records: validation and application of a census-based methodology. Am J Public Health. 1992;82(5):703-710.

16. Department of Health and Human Services: Panel on Antiretroviral Guidelines for Adult and Adolescents. Guidelines for the use of antiretroviral agents in HIV-1-infected adults and adolescents. In Department of Health and Human Services, ed2011:1-128. Available at: http://www.aidsinfo.nih.gov/contentfiles/lvguidelines/adultandadolescentgl.pdf

17. Sikka R, Xia F, Aubert RE. Estimating medication persistency using administrative claims data. Am J Manag Care. 2005;11(7):449-457.

18. Steiner JF, Prochazka AV. The assessment of refill compliance using pharmacy records: methods, validity, and applications. J Clin Epidemiol. 1997;50(1):105-116.

19. Steiner JF, Koepsell TD, Fihn SD, Inui TS. A general method of compliance assessment using centralized pharmacy records. Description and validation. Med Care. 1988;26(8):814-823.

20. Kitahata MM, Reed SD, Dillingham PW, et al. Pharmacy-based assessment of adherence to HAART predicts virologic and immunologic treatment response and clinical progression to AIDS and death. Int $J$ STD AIDS. 2004;15(12):803-810.

21. Fairley CK, Permana A, Read TR. Long-term utility of measuring adherence by self-report compared with pharmacy record in a routine clinic setting. HIV Med. 2005;6(5):366-369.
22. Horberg MA, Hurley LB, Silverberg MJ, Kinsman CJ, Quesenberry CP. Effect of clinical pharmacists on utilization of and clinical response to antiretroviral therapy. J Acquir Immune Defic Syndr. 2007;44(5):531-539.

23. Grossman HA. Addressing the need for HIV specialists: the AAHIVM perspective. AIDS Read. 2006;16(9):479-486.

24. HIV Medicine Association. Qualifications for Physicians Who Care for Patients with HIV Infection. 2010. Available from: http://www.hivma. org/Defining-HIV-Expertise.aspx

25. Horberg M, Silverberg M, Hurley L, Delorenze G, Quesenberry C. Influence of prior antiretroviral experience on adherence and responses to new highly active antiretroviral therapy regimens. AIDS Patient Care STDS. 2008;22(4):301-312.

26. Kitahata MM, Koepsell TD, Deyo RA, Maxwell CL, Dodge WT, Wagner EH. Physicians' experience with the acquired immunodeficiency syndrome as a factor in patients' survival. N Engl J Med. 1996;334(11): 701-706.

27. Kaiser Permanente. Kaiser Permanente HIV Challenge. 2012. Available from: http://www.kp.org/hivchallenge. Accessed March 23, 2012.

28. Kaiser Permanente HIV Initiative and Care Management Institute. Interregional HIV Treatment Practice Resource. 2011. Available from: http://info.kp.org/communitybenefit/html/our_work/global/ hivchallenge/images/HIV_Challenge_PDFs/KP\%20HIV\%20Care\%20 Treatment $\% 20$ Practice $\% 20$ Resource $\% 202011 \% 20$ FINAL.pdf. Accessed March 27, 2012.

29. Horberg MA, Hurley LB, Towner WJ, et al. Determination of optimized multidisciplinary care team for maximal antiretroviral therapy adherence. J Acquir Immune Defic Syndr. 2012;60(2):183-190.

30. Althoff KN, Justice AC, Gange SJ, et al. Virologic and immunologic response to HAART, by age and regimen class. AIDS. 2010;24(16) 2469-2479.

31. Silverberg MJ, Leyden W, Horberg MA, DeLorenze GN, Klein D, Quesenberry CP Jr. Older age and the response to and tolerability of antiretroviral therapy. Arch Intern Med. 2007;167(7):684-691.

32. Arnsten JH, Li X, Mizuno Y, et al. Factors associated with antiretroviral therapy adherence and medication errors among HIV-infected injection drug users. J Acquir Immune Defic Syndr. 2007;46 Suppl 2:S64-S71.

33. Wood E, Montaner JS, Yip B, et al. Adherence and plasma HIV RNA responses to highly active antiretroviral therapy among HIV-1 infected injection drug users. CMAJ. 2003;169(7):656-661.

34. Silverberg MJ, Leyden W, Quesenberry CP Jr, Horberg MA. Race/ ethnicity and risk of AIDS and death among HIV-infected patients with access to care. J Gen Intern Med. 2009;24(9):1065-1072.

35. The White House Office of National AIDS Policy. National HIV/AIDS Strategy for the United States. In: The White House Office of National AIDS Policy, ed2010. Available at: http:ljwww.whitehouse.gov/sites/ default/files/uploads/NHAS.pdf
HIV/AIDS - Research and Palliative Care

\section{Publish your work in this journal}

HIV/AIDS - Research and Palliative Care is an international, peerreviewed open-access journal focusing on advances in research in HIV, its clinical progression and management options including antivira treatment, palliative care and public healthcare policies to control viral spread. The journal welcomes original research, basic science,

\section{Dovepress}

clinical \& epidemiological studies, reviews \& evaluations, expert opinion \& commentary, case reports \& extended reports. The manuscript management system is completely online and includes a very quick and fair peer-review system. Visit http://www.dovepress.com/ testimonials.php to read real quotes from published authors. 